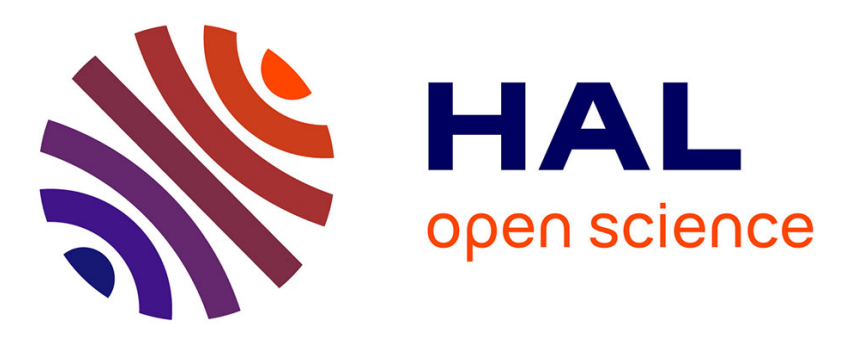

\title{
Thermal control and Energy balance in polymer processing
}

Rémi Deterre, Pierre Mousseau, Alain Sarda, Julien Launay

\section{To cite this version:}

Rémi Deterre, Pierre Mousseau, Alain Sarda, Julien Launay. Thermal control and Energy balance in polymer processing. 2019 European Conference on Constitutive Models for Rubber, Jun 2019, Nantes,

France. hal-02273094

\section{HAL Id: hal-02273094 \\ https://hal.science/hal-02273094}

Submitted on 28 Aug 2019

HAL is a multi-disciplinary open access archive for the deposit and dissemination of scientific research documents, whether they are published or not. The documents may come from teaching and research institutions in France or abroad, or from public or private research centers.
L'archive ouverte pluridisciplinaire HAL, est destinée au dépôt et à la diffusion de documents scientifiques de niveau recherche, publiés ou non, émanant des établissements d'enseignement et de recherche français ou étrangers, des laboratoires publics ou privés. 


\title{
Thermal control and Energy balance in polymer processing
}

\author{
R. Deterre, P. Mousseau, A. Sarda \\ GEPEA - OSE Université de Nantes
}

J. Launay

Capacités Université de Nantes

\begin{abstract}
The rubber industry is facing a lack of thermal control during rubber processing. In the process of injection molding of elastomers, improving the energy efficiency of the tools is a current challenge for industry in terms of energy consumption, productivity and product quality. Experimental measurements allow us to understand the thermal of the tool and to show the thermal heterogeneities on the surface of the mold and in the various cavities. Tests of injection molding of the rubber and a thermal balance on the energy consumption of the tool are carried out. In the rubber industry, $20 \%$ of the energy consumed by capital goods comes from heating processes; more than $50 \%$ of heat losses are linked to insufficient control and thermal insulation of Molds. The design of the tooling evolves in particular towards the reduction of the heated mass and the thermal insulation of the molds.
\end{abstract}

\section{INTRODUCTION}

Improving the energy efficiency of tooling is a challenge for rubber industries today in terms of energy consumption, productivity and product quality. The design of the tools evolves towards the reduction of the heated mass and the thermal insulation of the molds [(The Society of the Plastics Industry and Energy, 2005), (Smithers, 2007), (Project, 2007), (Report, 1998)]. In this work, we are interested in controlling and mastering the thermal regulation of a tool used in the shaping of the elastomeric materials. The aim is to propose a new approach of a tool design for the improvement of heat transfers and better control in parts quality.

We present the design and instrumentation of the experimental set-up. Experimental measurements allowed us to understand the thermal of the tool and to show the thermal heterogeneities on the surface of the mold and in the various cavities. Injection molding tests of the rubber and a thermal balance on the energy consumption of the tool were carried out.

\section{EXPERIMENTAL SET-UP}

\subsection{Rubber injection molding process}

The Figure 1 describes the injection device used for the samples molding. We used a vertical rubber injection molding machine (REP V39). The mold is fixed on two heating plates. The maximum clamp force is $110 \mathrm{~T}$.

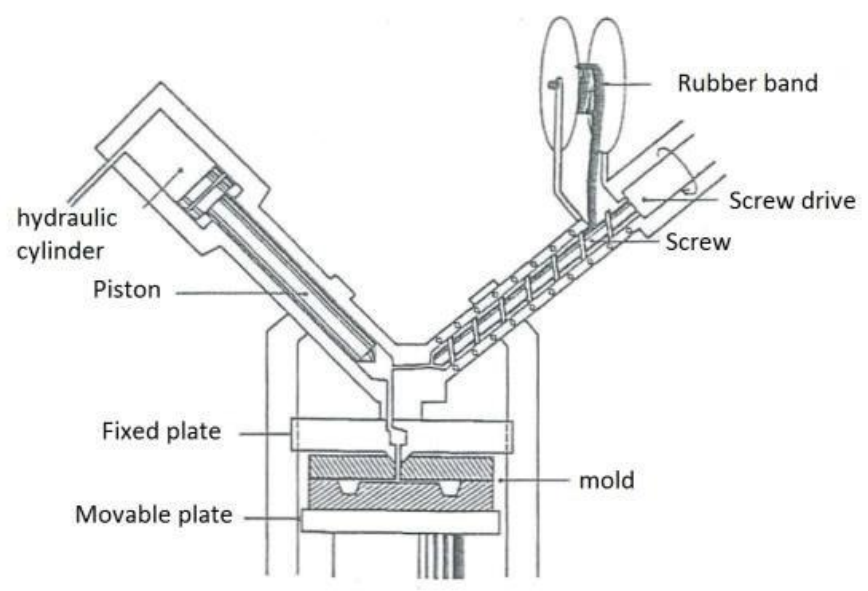

Figure 1: Injection molding press and mold.

The rubber is introduced into the storage jar at 70 ${ }^{\circ} \mathrm{C}$. In a second stage, the injection piston pushes the polymer inside the hot mold regulated at $180{ }^{\circ} \mathrm{C}$.

\subsection{Rubber injection molding process}

The Figure 2 describes the molded parts. 

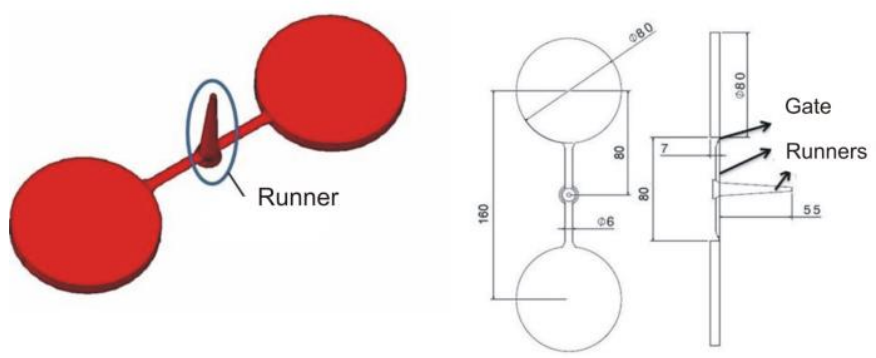

Figure 2: rubber parts and runners used in the experimental setup.

The rubber compound is based on EthylenePropylene-Diene Monomer matrix. The compound has a density of $1070 \mathrm{~kg} / \mathrm{m} 3$, a thermal conductivity of $0.298 \mathrm{~W} / \mathrm{m} / \mathrm{K}$ and a constant heat mass of 1490 $\mathrm{J} / \mathrm{kg} / \mathrm{K}$. we used a RPA (Rubber Process Analyzer) in order to measure the kinetics curves of the rubber compound vulcanization.

\subsection{Mold and thermal instrumentation}

The mold is equipped with thermal and pressure sensors (cf. Figure 3).

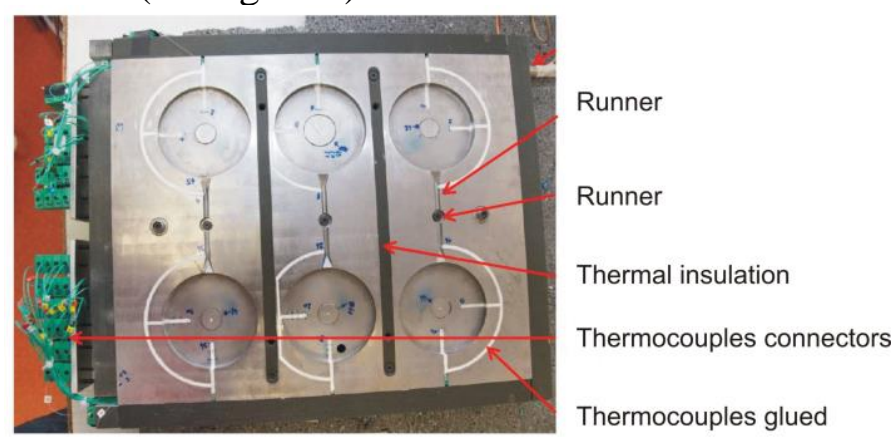

Figure 3: view of the mold cavities equipped with sensors.

The thermal device is able to measure the rubber temperature evolution in the channels and in the various cavities (Fekiri, et al., 2017).

\section{THERMO-KINETIC MODEL OF MOLDING}

The model geometry used for the numerical curing simulation is represented in Figure 4.

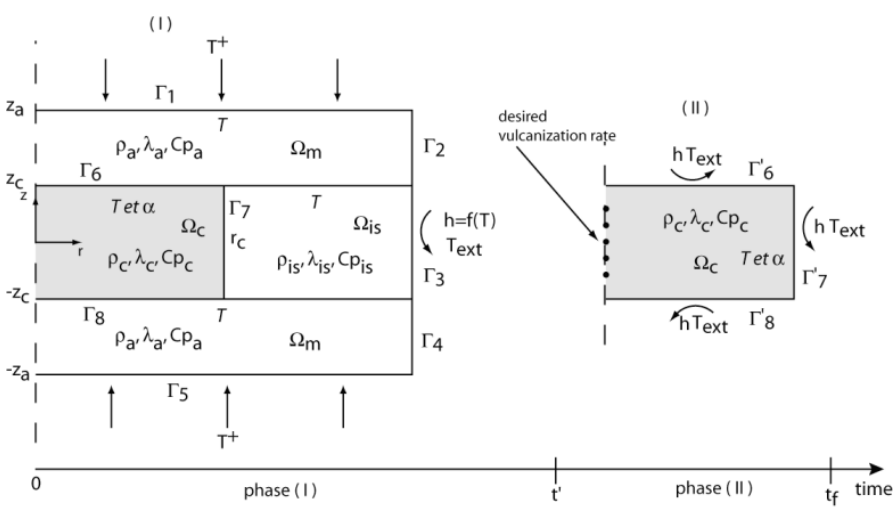

Figure 4: Schematic diagram of the model geometry.
Mould temperature regulation is imposed on the boundaries $\Gamma 1$ and $\Gamma 5 . \Omega \mathrm{m}$ represents the metal boundaries of the mould, $\Omega$ is represents the insulating guarding element and $\Omega \mathrm{c}$ represents the rubber part. $\mathrm{T}+$ represents the mould temperature that is to be prescribed for the optimized curing cycle.

During the phase (1) in Figure 2, heat transfer in the rubber part is described by equations (1),(2) and (3) with a source term related to the enthalpy of the vulcanization reaction.

$\rho_{\Omega_{c}} C p_{\Omega_{c}}(T) \frac{\partial T}{\partial t}=\lambda_{\Omega_{c}} \Delta T+\rho_{\Omega_{c}} \Delta H_{\Omega_{c}} \frac{\partial \alpha_{\Omega_{c}}}{\partial t}$

The boundary conditions of phase II are described by equations (8) and (9).

$T^{\prime}\left(t=t^{\prime}\right)=T\left(t=t^{\prime}\right)$

$-\left.\lambda_{c} \frac{\partial T^{\prime}}{\partial z}\right|_{\Gamma_{6}^{\prime}}=-\left.\lambda_{c} \frac{\partial T^{\prime}}{\partial r}\right|_{\Gamma_{7}^{\prime}}=\left.\lambda_{c} \frac{\partial T^{\prime}}{\partial z}\right|_{\Gamma_{8}^{\prime}}=h(T)\left[T^{\prime}-T_{e x t}\right]$

We used a modification of Isayev's model (induction + vulcanization) by adding a reversion model (equation 4-11), according to Coran's model (Coran, 1964).

$\frac{\partial \beta_{\Omega_{c}}}{\partial t}=[1-W(\tilde{t})] \cdot F(T)+W(\tilde{t}) \cdot G(\beta, T)+W(\tilde{t}) \cdot H(T)$

$W\left(\tilde{t}_{i}\right)=\left\{\begin{array}{lll}0 & \text { if } & \tilde{t}_{i}<1 \\ 1 & \text { if } & \tilde{t}_{i} \geq 1\end{array}\right.$

The reduced induction time $\tilde{t}_{i}$ is given in equation (12):

$\tilde{t}_{i}=\int_{0}^{t} \frac{d t}{t_{i}(\mathrm{~T}(\mathrm{t}, \mathrm{r}, \mathrm{z}))}$

With:

$t_{i}=t_{0} e^{\left(T_{B} / T\right)}$

The second term of equation (4), F, is defined as follows:

$F(\alpha, T)=n k^{1 / n} \alpha^{n-1 / n}(1-\alpha)^{n+1 / n}$

With:

$k=k_{0} \mathrm{e}^{(-E / R T)}$

The last terms (4) describe the reversion reaction.

$H(T)=-k_{r} \cdot e^{-k_{r}\left(t-t_{i}\right)}$

With:

$k_{r}=k_{r_{0}} \cdot \mathrm{e}^{\left(\frac{E_{r_{0}}}{R T}\right)}$

The temperature measurements used to validate the thermal model were recorded during various moulding cycles. The comparison between experi- 
mental measurements and our numerical model solution shows a good agreement. The comparison between experimental vulcanization values and the calculated ones showed, also, a good agreement.

\section{THERMAL BEHAVIOR OF RUBBER AND MOLD}

We investigate the temperature evolution depending from the part and the mold configurations.

\subsection{Viscous heating during filling}

The Figure 5 reports the surface temperature measured in the channel during the filling stage.

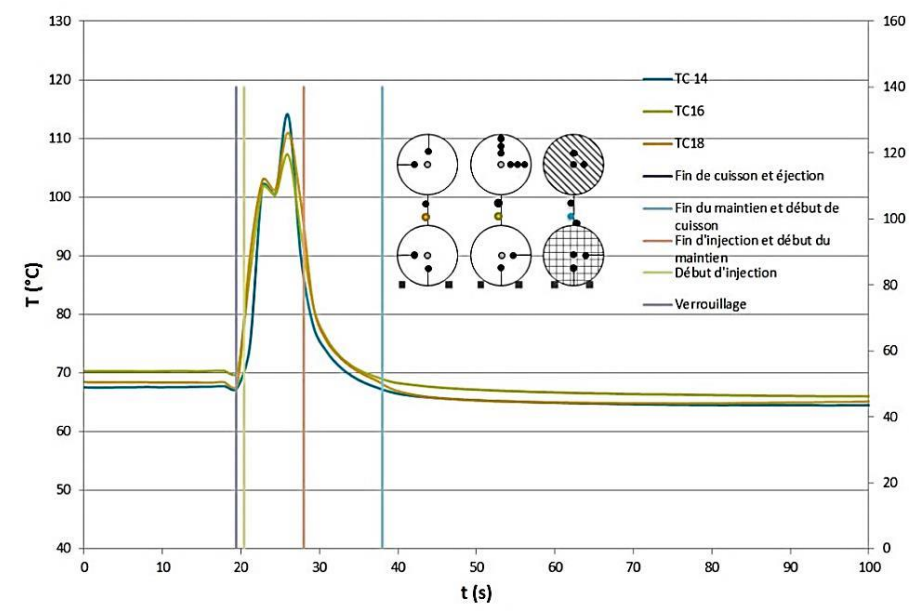

Figure 5: viscous heating measurements during filling stage.

We observe a temperature rise more than $30^{\circ} \mathrm{C}$ of the rubber during the filling stage. The magnitude of this value is 5 time higher than the average temperature rise corresponding to an adiabatic calculation (Agassant, et al., 2017). This is due to the high temperature gradient developed at the runner wall.

\subsection{Effect of the rubber part}

We used the thermal model developed previously, in order to simulate various industrial case studies. The following one concerns a rubber boots. The Figure 6 reports the temperature gradient in a mold section during a whole cycle.

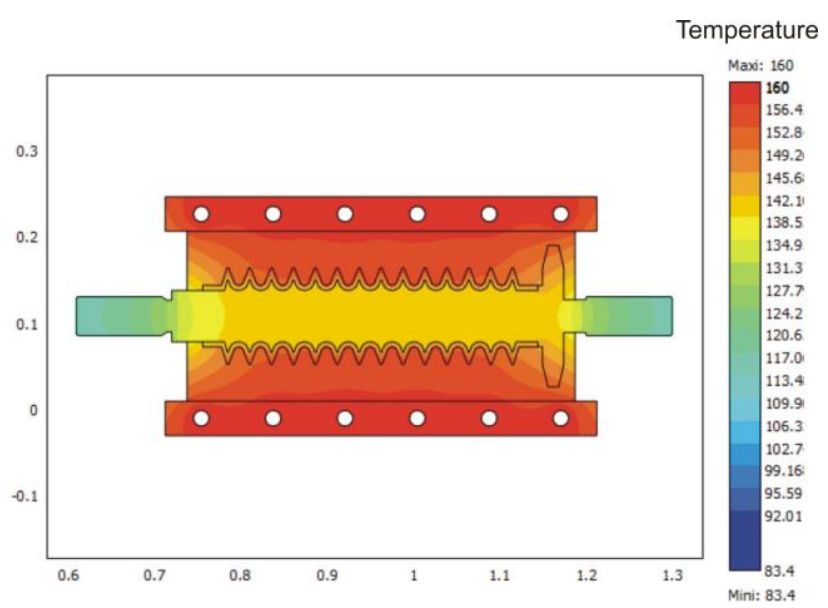

Figure 6: temperature and state of cure field during the molding of a boots.
We detect a big difference between the mold and the metal insert. This is due to the insulation effect due to the rubber presence in the cavity. Such effect induces thermal heterogeneity, especially for the metal inserts in the mold. Such a model is often use as a decision support tool in order to choose the best thermal conditions for the production setup.

\subsection{Effect of the part geometry}

The following case study shows the molding of various part geometries in the same mold. The Figure 7 reports the temperature gradient in a mold section.
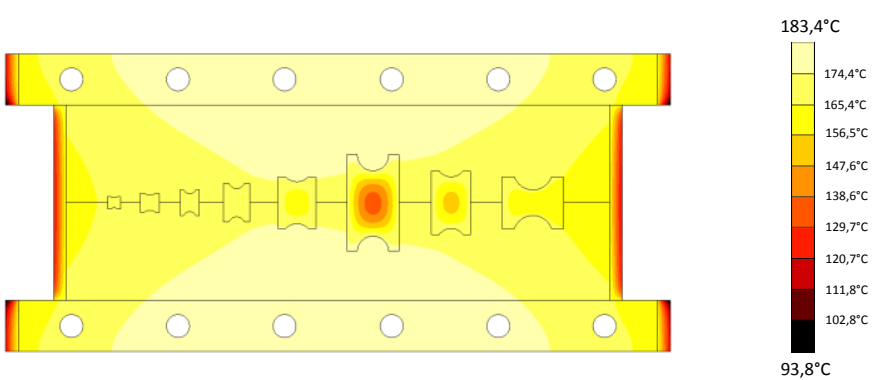

Thermal regulation temperature $=180^{\circ} \mathrm{C}$

Figure 7: temperature field in the cross section of a mold during the molding cycle of various parts in the same mold.

The Figure 8 shows the temperature versus time of various parts molded in the same mold.
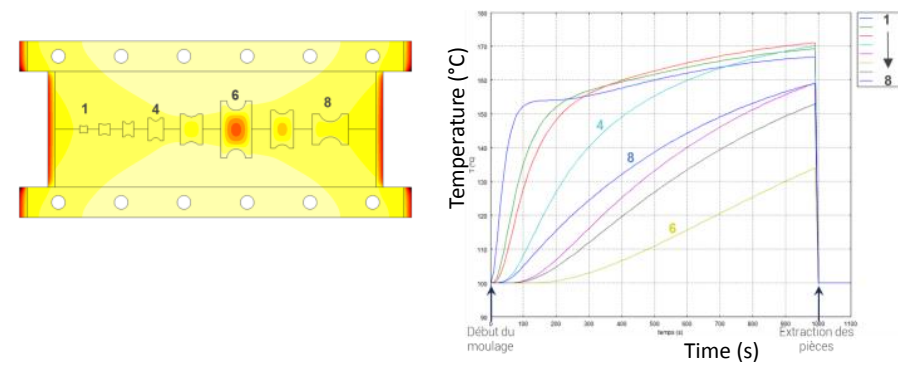

Figure 8: viscous heating measurement during filling stage.

We observe the big influence of the part geometry especially the part thickness effect. Nevertheless, such a model allows to predict and eventually to show the possibility to make various parts in the same mold. In another way, this model was used in order to mold various rubber compounds (with various cure kinetics) in various cavities in the same mold during the same molding cycle.

\subsection{Effect of the number of parts}

We studied the effect of the part number molded in the same mold. The Figure 9 shows the temperature and the cure evolution versus time in a multicavity mold. The curves compare the temperature and the state of cure of the central part with the peripheral one. 


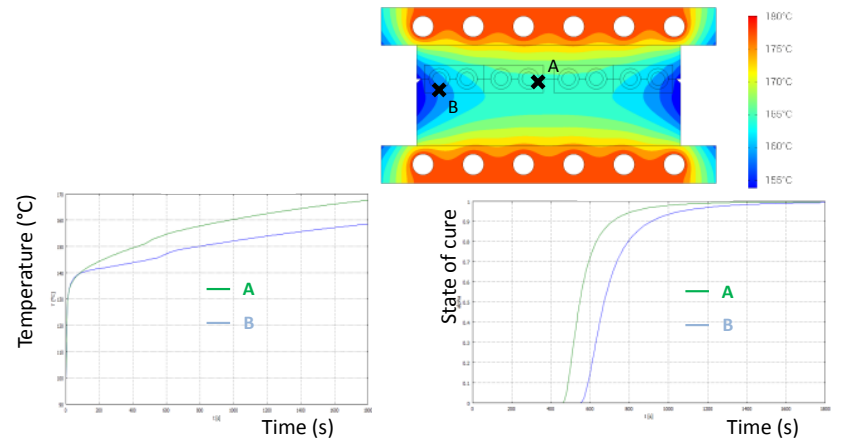

Figure 9: temperature and cure evolution during the molding of numerous parts.

Such analysis is necessary to determine the maximum number of parts and eventually to the thermal improvements necessary to undertake (e.g. thermal insulation).

\section{EFFECT OF PROCESS PARAMETERS}

We used the coupled rubber part and mold simulation in order to investigate the effect of various process parameters.

\subsection{Thermal cycling}

We measured the temperature evolution at various places in the mold versus time, in the previous industrial case study. The Figure 12 shows the various temperatures curves during many cycles with various cycle times.

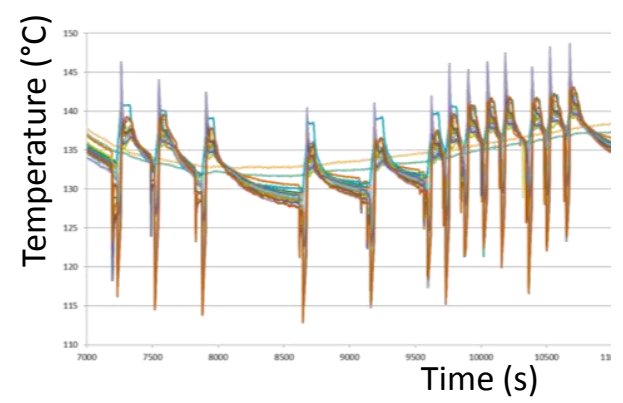

Figure 10: effect the cycle time variation on the mold temperature (at various places in the runners and the cavities).

We observe the unstationary thermal behavior of the mold. Such behavior should explain the effect of cycling change on the part quality.

\subsection{Thermal regulation}

The temperature measurements have been done in the same industrial case but with various thermal regulation conditions.

The Figure 11 shows effect of a classical regulation system (e.g. PID) on the temperature versus time evolution.

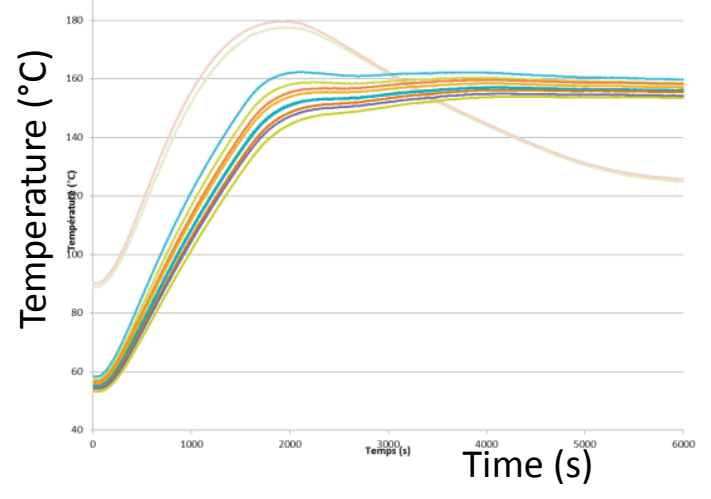

Figure 11: effect of the thermal regulation on the mold temperature at various places in the runners and the cavities.

We observe the temperature overshoot due to the thermal regulation effect.

A realistic modeling of the thermal regulation reveals a $15 \mathrm{~K}$ thermal gradient along an industrial thermal resistance. Such a gradient leads to a $5 \mathrm{~K}$ gradient at the mold surface.

Moreover, we simulate the effect of various regulation types. In the previous industrial case, a central regulation point leads to $180^{\circ} \mathrm{C}$ in the center and $160^{\circ} \mathrm{C}$ on the sides. In the same case, a 3 points regulation system results in $180^{\circ}$ in the center and $180^{\circ} \mathrm{C}+-1^{\circ} \mathrm{C}$ on the sides.

\section{ENERGY BALANCE IN RUBBER MOLDING}

The validated thermal model allows to calculate the energy balance during a molding cycle.

The Figure 12 illustrates the energy losses around a mold section.

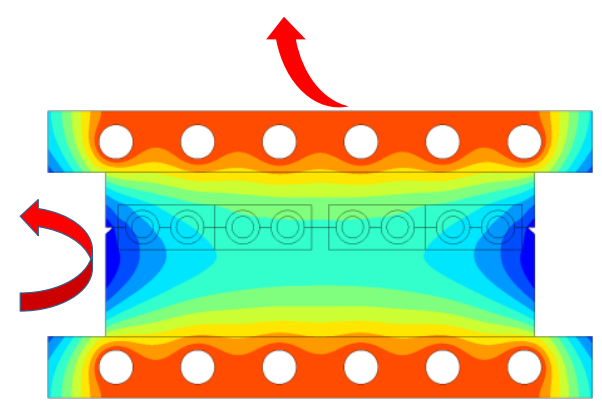

Figure 12: energy balance during molding cycle.

The energy balance corresponding to this case indicates the following repartition of the global energy spent during the whole molding cycle: $66 \%$ loss towards the press plates, $14 \%$ convection during mold opening, and $12 \%$ convection during the mold close phase. Such balance reveals also that less than $10 \%$ of the total energy is devoted to the vulcanization process.

\section{CONCLUSION}

The design of the tooling evolves in particular towards the reduction of the heated mass and the 
thermal insulation of the molds. Experimental measurements allow us to understand the thermal of the tool and to show the thermal heterogeneities on the surface of the mold and in the various cavities. Tests of injection molding of the rubber and a thermal balance on the energy consumption reveals that $20 \%$ of the energy consumed by capital goods comes from heating processes. More than $50 \%$ of heat losses are linked to inadequate control and thermal insulation of molds.

A. Coran (1964). Vulcanization. Part VI. A model and treatment for scorch delay kinetics. Rubber Chemistry and Technology, 37: 689-697.

J.-F. Agassant, P. Avenas, P. J. Carreau, B. Vergnes and M. Vincent (2017). Polymer processing: principles and modeling. Carl Hanser Verlag GmbH Co KG.

Report, United Nations Industrial Development Organization (UNIDO). Ministry of International Trade and Industry (MITI), Japan, Hanoi, 1998.

The Society of the Plastics Industry, U.S.D.o. Energy, in: I. The Society of the Plastics Industry (Ed.), U.S. Department of Energy, Washington, DC, 2005.

N. Fekiri, C. Canto, Y. Madec, P. Mousseau, C. Plot and A. Sarda (2017). Design and thermal analysis of a mold used in the injection of elastomers. AIP Con-ference Proceedings, 1896: 120009. 